\title{
HUBUNGAN FAKTOR DEMOGRAFI DAN PERILAKU SEKSUAL TERHADAP KEJADIAN INFEKSI MENULAR SEKSUAL PADA WANITA PEKERJA SEKS
}

\author{
Yuli Fitriasih $^{1}$., Nurhalim Shahib ${ }^{2}$., Farid $^{3}$ \\ ${ }^{1}$ Program Studi Pendidikan Sarjana dan Profesi Bidan (PS-PSPB) Fakultas Kedokteran \\ Universitas Sultan Agung Semarang \\ ${ }^{2}$ Program Studi Pascasarjana Fakultas Ilmu Kedokteran Dasar UNPAD \\ ${ }^{3}$ Program Studi Pascasarjana Kebidanan Fakultas Kedokteran UNPAD \\ yuli.fitriasih@gmail.com, farid_husin@yahoo.com
}

\begin{abstract}
Sexually transmitted infections are infections that can be spread through vaginal, anal or oral. Female sex workers particularly at risk for sexually transmitted infections. Preliminary studies in Cilacap district STI clinic in 2011 showed that the incidence of sexually transmitted infections is still quite high (60.81\%). Complex causal factors cause the difficulty of breaking the chain of IMS. This study aims to analyze the relationship between demographic factors and high-risk sexual behavior of high risk on the incidence of sexually transmitted infections and the risk factors on the incidence of sexually transmitted infections in female sex workers. Analytic survey research through case-control study (case-control) with a total sampling on 70 female sex workers in brothels Slarang conducted during the month of November 2013. Questionnaire as a means of collecting research data. Univariate analysis to determine the frequency distribution of incidence of STIs. Bivariate analysis using contingency coefficient test. Multivariate analysis using logistic regression. The results showed that there is a significant association between the incidence of STIs in high-risk demographic factors with $r$ value (0.239) and p-value (0.040), there is a significant association between the incidence of STIs in high-risk sexual behavior factors with values of r $(0.307 ; 0.230)$ and the p-value $(0.007 ; 0.048)$ respectively. Multivariate analysis showed that condom use is not routine is that most risk factors on the incidence of sexually transmitted infections in female sex workers with OR value 5.835. Conclusions of the study: female sex workers who do not regularly use condoms have 5.835 times greater risk for sexually transmitted infections. A total of 65\% the proportion of female sex workers suffer preventable sexually transmitted infection, if condom use.
\end{abstract}

Keywords : female sex workers, demographic factors, sexual behavior factors, sexually transmitted infections

\section{PENDAHULUAN}

Infeksi menular seksual (IMS) adalah infeksi yang dapat disebarkan melalui hubungan seks vaginal, anal atau oral. IMS ditularkan dari individu ke individu lain melalui kontak dengan kulit, alat kelamin, mulut, anus, atau cairan tubuh (The American College of Obstetricians and Gynecologists. Sexually Transmitted Diseases, 2010). Angka kejadian IMS dari tahun ke tahun mengalami peningkatan. Jumlah kasus baru IMS di Propinsi Jawa Tengah pada tahun 2011 adalah 10.752 kasus. Meskipun kemungkinan banyak kasus yang sebenarnya belum terdeteksi.

Kabupaten Cilacap dengan perkembangan industri dan adanya pelabuhan Tanjung Intan sebagai satu-satunya pelabuhan di perairan Jawa bagian selatan semakin memicu maraknya pekerja seks komersial (BPS Propinsi Jawa Tengah, 2008; John, 1997). Sehingga tahun 2006, kabupaten Cilacap telah memiliki klinik IMS (Komisi Penanggulangan AIDS, 2010). Kenyataannya, pada tahun 2011 kejadian IMS masih cukup tinggi, dari 780 orang pekerja seks komersial yang berkunjung, 60,81\% diantaranya menderita 
IMS. Faktor yang berhubungan terhadap kejadian IMS sangatlah kompleks, diantaranya adalah faktor demografi dan perilaku seksual. Faktor demografi berisiko tinggi diantaranya umur, pendidikan dan status pernikahan, sedangkan perilaku seksual berisiko tinggi meliputi penggunaan kondom dan cara melakukan hubungan seksual (Ohene and Akoto, 2008; Oralia., dkk, 2010; Verra dan Taufan, 2011).

\section{METODOLOGI}

Penelitian dengan pendekatan casecontrol, pada bulan November 2013. Subjek penelitian adalah wanita pekerja seks (WPS) yang periksa di klinik IMS Kabupaten Cilacap periode Januari-Desember 2012, dengan kriteria inklusi WPS yang datang memeriksakan diri di klinik IMS kabupaten Cilacap dengan diagnosis IMS dan bukan IMS. Instrument penelitian dengan kuesioner yang disusun sendiri. Analisis univariabel dilakukan dengan distribusi frekuensi, analisis bivariabel dengan uji koefisien kontingensi dan analisis multivariabel dengan uji regresi logistik. Penelitian ini dilakukan pada WPS di lokalisasi Slarang periode Nopember 2013 yang memenuhi kriteria inklusi.

\section{Hasil dan Pembahasan}

\section{Hasil}

Tabel 1.1 Kesetaraan Karateristik Subjek Penelitian

\begin{tabular}{|c|c|c|c|c|c|c|}
\hline \multirow{3}{*}{$\begin{array}{c}\text { Karakteristik } \\
\text { Subjek Penelitian }\end{array}$} & \multicolumn{4}{|c|}{$\begin{array}{c}\text { Infeksi Menular } \\
\text { Seksual } \\
\end{array}$} & \multirow{3}{*}{$\mathbf{X}^{2}$} & \multirow{3}{*}{$\begin{array}{l}\text { Nilai } \\
\text { p* }\end{array}$} \\
\hline & \multicolumn{2}{|c|}{$\begin{array}{c}\text { Kasus } \\
\text { (Terinfeksi) }\end{array}$} & \multicolumn{2}{|c|}{$\begin{array}{c}\text { Kontrol } \\
\text { (Tidak } \\
\text { terinfeksi) }\end{array}$} & & \\
\hline & $\mathbf{n}$ & $\%$ & $\mathbf{n}$ & $\%$ & & \\
\hline \multicolumn{7}{|l|}{ Umur } \\
\hline$-=24$ tahun & 20 & 71,4 & 17 & 40,5 & & \\
\hline$->24$ tahun & 8 & 28,6 & 25 & 59,5 & 6,459 & 1,245 \\
\hline \multicolumn{7}{|l|}{ Pendidikan } \\
\hline$-\mathrm{SD}$ & 18 & 64,3 & 19 & 45,2 & 2446 & 0766 \\
\hline$->\mathrm{SD}$ & 10 & 35,7 & 23 & 54,8 & 2,440 & 0,106 \\
\hline \multicolumn{7}{|l|}{ Status pernikahan } \\
\hline - Janda & 19 & 67,9 & 23 & 54,8 & & \\
\hline $\begin{array}{l}\text { - Bukan janda (belum } \\
\text { atau menikah) }\end{array}$ & 9 & 32,1 & 19 & 45,2 & 1,200 & 0,537 \\
\hline
\end{tabular}

Hasil analisis uji kesetaraan (homogenitas) menunjukkan kejadian IMS pada kelompok kasus dengan kontrol tidak berbeda secara bermakna ditinjau dari aspek umur, pendidikan dan status pernikahan atau dengan kata lain tidak setara $(p>0,05)$ dengan kejadian infeksi menular seksual. Hal ini dapat disimpulkan bahwa kedua kelompok penelitian adalah homogen sehingga layak untuk dapat dibandingkan. 
Tabel 1.2 Hubungan Faktor Demografi Terhadap Kejadian Infeksi Menular Seksual Pada Wanita Pekerja Seks Berdasarkan Skoring

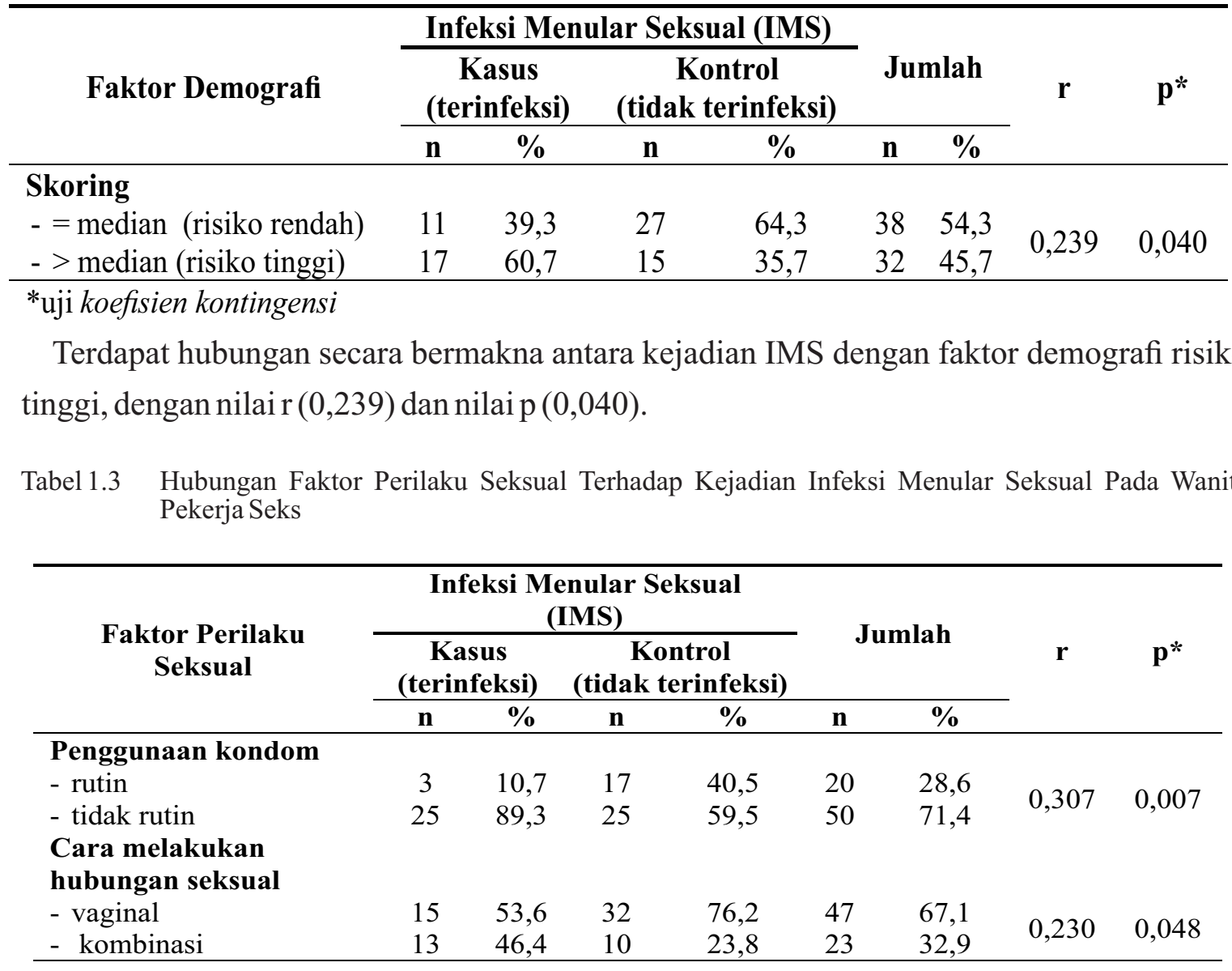

*uji koefisien kontingensi

Terdapat hubungan secara bermakna antara kejadian IMS dengan perilaku seksual risiko tinggi (penggunaan kondom tidak rutin, cara melakukan hubungan seksual kombinasi) dengan nilai $r(0,307 ; 0,230)$ dan nilai $p(0,007 ; 0,048)$ secara berturut-turut.

Tabel 1.4 Analisis Faktor Yang Paling Berisiko Terhadap Kejadian Infeksi Menular Seksual Pada Wanita Pekerja Seks

\begin{tabular}{|c|c|c|c|c|c|}
\hline Model & Variabel & Koefisien B & S.E (B) & Nilai $p^{*}$ & OR (IK 95\%) \\
\hline \multirow{4}{*}{$\begin{array}{l}\text { Model } \\
\text { akhir }\end{array}$} & Faktor demografi & 1,504 & 0,597 & 0,012 & $\begin{array}{c}4,498 \\
(1,396-14,490)\end{array}$ \\
\hline & Penggunaan kondom tidak rutin & 1,764 & 0,739 & 0,017 & $\begin{array}{c}5,835 \\
(1,370-24,855)\end{array}$ \\
\hline & $\begin{array}{l}\text { Cara melakukan hubungan } \\
\text { seksual kombinasi }\end{array}$ & 1,111 & 0,611 & 0,069 & $\begin{array}{c}3,036 \\
(0,917-10,053)\end{array}$ \\
\hline & Konstanta & $-1,361$ & & & \\
\hline
\end{tabular}

*uji regresi logistic

Variabel yang paling berisiko terhadap kejadian infeksi menular seksual pada wanita pekerja seks adalah penggunaan kondom tidak rutin dengan nilai OR 5,835. Artinya penggunaan kondom tidak rutin memiliki risiko 5,835 kali lebih besar untuk menyebabkan infeksi menular seksual dibandingkan penggunaan kondom rutin. 
Tabel 1.5 Analisis PAR (Population Attributable Risk) Pada Variabel Dominan Penggunaan Kondom Tidak Rutin Terhadap Kejadian Infeksi Menular Seksual Pada Wanita Pekerja Seks

\begin{tabular}{lccc}
\hline \multicolumn{1}{c}{ Variabel } & $\begin{array}{c}\text { Terinfeksi IMS } \\
\text { Kasus } \\
\text { n (28) }\end{array}$ & $\begin{array}{c}\text { Tidak Terinfeksi IMS } \\
\text { Kontrol } \\
\text { n (42) }\end{array}$ & $\begin{array}{c}\text { PAR* } \\
\text { \% }\end{array}$ \\
\hline Penggunaan kondom & & & 65 \\
- Tidak rutin & 25 & 25 & 65 \\
- Rutin & 3 & & \\
\hline *PAR & & & \\
\hline
\end{tabular}

Sebanyak 65\% proporsi wanita pekerja seks yang menderita infeksi menular seksual dapat dicegah, bila semua wanita pekerja seks menggunakan kondom rutin.

\section{Pembahasan}

Penelitian menunjukkan terdapat hubungan secara bermakna antara kejadian IMS dengan faktor demografi dengan nilai $r$ $(0,239)$ dan nilai $p(0,040)$.

Kondisi demografi suatu wilayah sangat berpengaruh terhadap kehidupan orang yang tinggal di wilayah tersebut. Pengaruh budaya, pertumbuhan penduduk, struktur sosial ekonomi bahkan modernisasi. Wilayah yang dipandang mampu memberikan jaminan kehidupan yang layak secara ekonomi menjadi sasaran utama urbanisasi. Salah satu dampak negatif arus urbanisasi adalah munculnya prostitusi (Susatyo, 2006).

Kabupaten Cilacap memiliki letak strategis dengan kemajuan industri, potensi perikanan serta terdapat pelabuhan (BPS Propinsi Jawa Tengah, 2008). Pelabuhan ikut memicu terbukanya hubungan yang luas serta memicu maraknya pekerja seks komersial. Pelabuhan Tanjung Intan Cilacap sebagai pelabuhan niaga satu-satunya di Jawa bagian selatan, tidak bisa dipisahkan dari ramainya anak buah kapal (ABK) yang turun ke darat menunggu kapalnya kembali berlayar. ABK yang singgah di Cilacap tidak luput dari mencari hiburan, termasuk wanita pekerja seks komersial (John, 1997). Belum lagi perkembangan industri yang sangat pesat di kabupaten Cilacap, antara lain adanya Pertamina, Semen Holcim, dan PLTU Bontan yang sering kali mendatangkan mentor dari negara lain guna pengembangan produktivitasnya. Seperti halnya para ABK, para mentor juga memerlukan hiburan karena mereka menetap dalam waktu yang cukup lama pula, termasuk salah satunya wanita pekerja seks.

Hasil penelitian menunjukkan bahwa kejadian IMS masih cukup tinggi pada kelompok umur $\leq 24$ tahun yaitu $71,4 \%$. Fenomena pekerja seks, dimana mereka menggunakan keadaan fisik tubuhnya sebagai sesuatu yang layak untuk dinilai dengan uang. Harga yang ada merupakan kesepakatan kedua belah pihak tanpa ada yang merasa dirugikan dan kedua belah pihak merasa puas (Public Health Agency of Canada, 2006). Semakin cantik dan muda, maka akan semakin tinggi tarifnya. Bahkan tidak membutuhkan ketrampilan/ skill, tidak memerlukan inteligensi tinggi, mudah dikerjakan asal orang yang bersangkutan 
memiliki kecantikan, kemudaan, dan keberanian (Kartini, 2011).

Wanita pekerja seks dengan umur $\leq 24$ tahun cenderung memiliki jumlah pelanggan lebih banyak jika dibandingkan dengan yang sudah berumur dan jumlah hubungan seksual yang mereka lakukan cukup tinggi. Mereka mengandalkan kecantikan wajah maupun tubuhnya dan tampil mencolok serta dapat merangsang selera seks kaum pria. Wanita pekerja seks umur $\leq 24$ tahun lebih aktif secara seksual dan akan meningkatkan risiko terjadinya IMS (Kartini, 2011).

Sejalan dengan penelitian pada wanita pekerja seks di Filipina. Wanita pekerja seks dengan umur 14-17 tahun memiliki kesadaran yang rendah untuk menggunakan kondom rutin saat berhubungan seksual dengan pelanggan dibandingkan pada kelompok umur 35-48 tahun (Lianne., dkk, 2012). Meningkatnya risiko IMS pada wanita pekerja seks umur muda, selain lebih aktif secara seksual dan rendahnya kesadaran menggunakan kondom juga dihubungkan dengan belum matangnya pertumbuhan saluran genitalia sehingga lebih mudah terjadi perlukaan atau sobek saat melakukan hubungan seksual (Lianne., dkk, 2012; Department of Health and Human Services Centers For Disease Control and Prevention, 2012).

Hal ini sejalan dengan penelitian yang dilakukan di Vietnam Utara bahwa umur muda wanita pekerja seks akan berpengaruh terhadap frekuensi hubungan seksual yang dilakukan, sehingga akan meningkatkan risiko infeksi menular seksual (Nguyen., dkk, 1998).
Pendidikan berpengaruh terhadap kemampuan seseorang dalam memahami informasi yang diterima. Rendahnya tingkat pendidikan menyebabkan rendahnya kemampuan mereka dalam memahami suatu informasi atau pengetahuan yang diperolehnya, sehingga wanita pekerja seks masih banyak yang enggan untuk menggunakan kondom saat melakukan hubungan seksual dengan pelanggan. Pendidikan juga berpengaruh terhadap perilaku berpraktik yang baik yaitu dalam hal ini selalu menggunakan kondom saat berhubungan seksual dengan pelanggan (Edy, 2009; Dewi and Ernestina, 2012).

Latar belakang pendidikan wanita pekerja seks yang terdiagnosis IMS di lokalisasi Slarang terbanyak hanya tamat SD $(64,3 \%)$, menyebabkan kemampuan mereka untuk menerima informasi terbatas. Berdasarkan studi pendahuluan di klinik IMS, kegiatan penyuluhan tentang IMS sudah sering sekali diadakan bahkan setiap ada pasien memeriksakan diri, maka terlebih dahulu diberikan informasi tentang IMS. Kondom juga dibagikan secara cuma-cuma (gratis) bagi mereka. Namun, pada kenyataannya angka kejadian IMS masih cukup tinggi dikalangan pekerja seks serta masih rendahnya penggunaan kondom rutin. Rendahnya kesadaran mereka untuk menggunakan kondom rutin lebih terletak pada rasa takut akan kehilangan pelanggan dan penghasilan.

Kejadian IMS terbanyak pada status pernikahan janda (67,9\%). Status janda mencari pelanggan sebanyak-banyaknya untuk mendapatkan uang agar tetap bisa menghidupi keluarganya (Edy, 2009). Salah 
satu penyebab munculnya pelacuran adalah adanya tekanan ekonomi, faktor kemiskinan, pertimbangan ekonomis untuk mempertahankan hidupnya (Kartini, 2011). Seorang janda menjadi tulang punggung dalam keluarga. Desakan kebutuhan hidup menyebabkan janda melangkah pada jalan yang termudah untuk mendapatkan uang.

Pekerja seks komersial tidak memerlukan keahlian apapun, bahkan tidak membutuhkan persyaratan pendidikan formal. Hanya bermodalkan wajah yang cantik dan tubuh yang bagus mereka sudah dapat memperoleh uang (Edy, 2009).

Status janda yang hanya mengandalkan penghasilan dari dirinya memaksa untuk mencari pelanggan yang banyak bagi solusi mereka. Dengan demikian, kebutuhan hidupnya dan keluarga dapat terpenuhi. Frekuensi hubungan seksual yang meningkat akan meningkatkan pula risiko terjadinya IMS (Edy, 2009).

Penelitian menunjukkan terdapat hubungan secara bermakna antara kejadian IMS dengan faktor perilaku seksual risiko tinggi (penggunaan kondom tidak rutin, cara melakukan hubungan seksual kombinasi) dengan nilai $\mathrm{r}(0,307 ; 0,230)$ dan nilai $\mathrm{p}(0,007$; $0,048)$ secara berturut-turut.

Penggunaan kondom rutin dan tepat dapat menurunkan risiko kejadian IMS. Penelitian laboratorium menunjukkan bahwa kondom latek memiliki membran impermeabel yang tidak dapat dilalui oleh patogen penyebab IMS. Sifat fisik kondom lateks menyediakan penghalang untuk sekresi genital yang mengirimkan organisme penyebab IMS.
Dengan demikian perlindungan yang diberikan sangat baik (Department of Health and Human Services Centers For Disease Control and Prevention. Condoms and STDs, 2012).

Sejalan dengan penelitian di Jepang. Hasil penelitian menunjukkan bahwa terdapat hubungan penggunaan kondom dengan infeksi menular seksual, dengan nilai $\mathrm{p}(<0,001)$ (Masako., dkk, 2010).

Penelitian lain yang dilakukan terhadap 968 wanita pekerja seks di Vietnam Selatan juga menunjukkan bahwa 35\% pekerja seks selalu menggunakan kondom, 43\% kadangkadang menggunakan kondom, dan 22\% tidak pernah menggunakan kondom dalam kontak seksual. Sedangkan pada analisis multivariate diperoleh hasil bahwa risiko kejadian infeksi menular seksual meningkat 1 sampai 8 kali pada wanita pekerja seks yang tidak rutin menggunakan kondom, dengan nilai odds rasio = 1,01-8,0 (Nguyen., dkk, 1998).

Melakukan hubungan seksual dengan pasangan yang terinfeksi tanpa menggunakan kondom akan meningkatkan risiko IMS (Departement of Health and Human Services Centers for Disease Control and Prevention, 2008). Sejalan dengan penelitian yang dilakukan di Kenya menunjukkan bahwa $40,8 \%$ dari wanita pekerja seks pernah melakukan seks anal dan 74,2\% dari wanita pekerja seks yang melakukan hubungan seks anal memiliki risiko lebih besar atau samasama berisiko tinggi untuk terjadinya IMS dibandingkan dengan seks vaginal. Hasil analisis dengan regresi logistik ganda 
menunjukkan bahwa hubungan seks anal secara signifikan berhubungan dengan kejadian IMS $(\mathrm{p}<0,05)$ (Schwandt., dkk, 2006).

Hasil penelitian menunjukkan bahwa variabel yang paling berisiko terhadap kejadian IMS adalah penggunaan kondom tidak rutin. Wanita pekerja seks yang tidak rutin menggunakan kondom saat melakukan hubungan seksual dengan pelanggan memiliki risiko 5,835 kali lebih besar untuk menderita IMS dibandingkan wanita pekerja seks yang selalu menggunakan kondom.

Perlindungan kondom terhadap penularan IMS sangatlah efektif. Umur pekerja seks, pendidikan, status pernikahan dan cara melakukan hubungan seksual pada dasarnya akan tetap mengarah pada bagaimana kedisiplinan terhadap penggunaan kondom.

Sejalan dengan penelitian terhadap 968 wanita pekerja seks di Vietnam Selatan menunjukkan bahwa penggunaan kondom merupakan faktor yang paling berisiko terhadap kejadian IMS, dimana risiko kejadian infeksi menular seksual meningkat 1 sampai 8 kali pada wanita pekerja seks yang tidak rutin menggunakan kondom, dengan nilai Odds Rasio = 1,01-8,0 (Nguyen., dkk, 1998).

Diperkuat dengan hasil analisis PAR (population attributable risk) dimana menunjukkan hasil bahwa $65 \%$ proporsi wanita pekerja seks dapat dicegah menderita infeksi menular seksual, bila rutin menggunakan kondom (penggunaan kondom tidak rutin dihilangkan).

\section{SIMPULAN DAN SARAN}

\section{Simpulan}

Sebanyak $65 \%$ proporsi wanita pekerja seks dapat dicegah menderita IMS, bila rutin menggunakan kondom (penggunaan kondom tidak rutin dihilangkan).

\section{Saran}

Penelitian lebih lanjut dengan desain kualitatif agar dapat menjawab teknik penggunaan kondom yang dilakukan. Dinas kesehatan kabupaten Cilacap harus melakukan berbagai upaya untuk menurunkan kejadian IMS. Bekerjasama dengan pihak-pihak lain untuk melakukan pelatihan dan pembekalan bagi wanita pekerja seks agar mereka beralih profesi. Memberikan pendidikan kesehatan tentang pentingnya penggunaan kondom baik pada pria maupun wanita.

\section{DAFTAR PUSTAKA}

Badan Pusat Statistik (BPS) Propinsi Jawa Tengah. 2008. Profil Kabupaten Cilacap. Department of Health and Human Services Centers For Disease Control and Prevention. 2012. Condoms and STDs: fact sheet for public health personnel.

Departement of Health and Human Services Centers for Disease Control and Prevention. 2008. Sexually Transmitted Infections in developing countries: current concepts and strategies on improving STI prevention, treatment, and control.

Dewi IP, Ernestina C. 2012. Transactional Sex risk across a typology of rural and urban female sex workers in Indonesia: A Mixed Methods Study. Plos One. 2012;7 (12):1-12.

Edy W. 2009. Praktik wanita pekerja seks (WPS) dalam pencegahan penyakit infeksi menular seksual (IMS) dan HIV\&AIDS di lokalisasi Koplak, Kabupaten Grobogan. Jurnal Promosi Kesehatan Indonesia. 2009;4(2):94102. 
John Mc. Lokasi praktek WTS liar yang dikhawatirkan jadi sumber AIDS. Harian Umum Pikiran Rakyat. Senin, 7 April 1997.

Kartini K. 2011. Patologi sosial Jilid 1. Jakarta: PT. Raja Grafindo Persada.

Komisi Penanggulangan AIDS. 2010. Strategi nasional penanggulangan HIV dan AIDS 2007-2010.

Lianne AU, Robert MM, Nina CS, and Donald EM. 2012. Age differences among female sex workers in the Philippines: sexual risk negotiations and perceived manager advice. AIDS Research and Treatment. 2012:7.

Masako OK, Tatsuya Sato, Hideko Kato, Sonia PS, Saman Z, Masahiro K. 2010. Demographic and behavioral characteristics of non-sex worker females attending sexually transmitted disease clinics in Japan: a nationwide case-control study. BMC Public Health. 2010;10:106.

M Schwandt, C Morris, A Ferguson, E Ngugi, S Moses. 2006. Anal and dry sex in commercial sex work, and relation to risk for sexually transmitted infections and HIV in Meru, Kenya. Sex Transm Infect.;82:392-396.

Nguyen TH, Vo TN, Nguyen VT, Truong XL, Ha BK. 1998. HIV infection and risk factors among female sex workers in Southern Vietnam. Journal AIDS. 1998;12:425432.

Ohene and Akoto. Factors associated with sexually transmitted infections among young Ghana women. Ghana Medical Journal. 2008;42(3):96-100.

Oralia L, Steffanie AS, Gustavo AM, Remedios L, Victoria DO, et al. Risk factors associated with chlamydia and gonorrhea infection among female sex workers in two Mexico-U.S. border cities. Int J STD AIDS. 2010; 21(7):1-13.

Public Health Agency of Canada. Canadian guidelines on sexually transmitted infections: specific populations sex workers. Edisi 2006.

Susatyo AP. 2006. Dampak perkembangan kota terhadap lingkungan sosial masyarakat. Teodolita. 2006;7(1):46-55.

The American College of Obstetricians and Gynecologists. 2010. Sexually Transmitted Diseases. ACOG Committee on Adolescent Health Care.
Verra S, Taufan N. 2011. Mengungkap tuntas 9 jenis PMS (Penyakit Menular Seksual). yogyakarta: Nuha Medika. 